\title{
KUALITAS HIDUP MAHASISWA PROFESI APOTEKER DENGAN HEALTH RELATED QUALITY OF LIFE (HRQOL) SF-6D DI FAKULTAS FARMASI UNIVERSITAS AHMAD DAHLAN YOGYAKARTA
}

\author{
QUALITY OF LIFE OF PHARMACY STUDENT USING HEALTH \\ RELATED QUALITY OF LIFE (HRQOL) SF-6D QUESTIONNAIRE IN \\ FACULTY OF PHARMACY AHMAD DAHLAN UNIVERSITY \\ YOGYAKARTA
}

\author{
Ana Hidayati , Farida Nur Mufliha, Imaniar Noor Faridah \\ Fakultas Farmasi Universitas Ahmad Dahlan \\ Email: ana.hidayati@pharm.uad.ac.id
}

\begin{abstract}
ABSTRAK
Kualitas hidup individu dipengaruhi oleh status kesehatannya masing-masing. Individu sehat maupun sakit dapat diukur kualitas hidupnya. Pengukuran menggunakan instrumen Short Form 36 (SF-36). Penelitian bertujuan untuk mengetahui nilai kualitas hidup dan faktor-faktor yang mempengaruhi kualitas hidup mahasiswa. Penelitian ini menggunakan rancangan crossectional. Sampel merupakan mahasiswa Program Studi Profesi Apoteker angkatan XXXI di Fakultas Farmasi Universitas Ahmad Dahlan yang diberi kuesioner SF-36 dan form karakteristik sampel. Analisis untuk SF-36 dipetakan ke SF-6D dan data karakteristik dinyatakan dalam presentase. Analisis hubungan antara karakteristik sampel dengan kualitas hidup dilakukan dengan Uji Mann-Whitney dan KruskalWallis. Jumlah subyek yang digunakan pada penelitian berjumlah 126 mahasiswa. Hasil kualitas hidup mahasiswa profesi apoteker pada SF-6D menunjukkan skor sebesar 0,739. Hasil uji antara skor kualitas hidup dengan karakteristik menunjukkan adanya hubungan dengan kualitas hidup pada jenis transportasi ( $\mathrm{p}=0,039$ ) dan riwayat penyakit $(\mathrm{p}=0,01)$. Berdasarkan hasil penelitian dapat disimpulkan bahwa skor kualitas hidup mahasiswa dari SF Indeks pada SF-6D yaitu 0,739. Faktor yang mempengaruhi kualitas hidup mahasiswa adalah transportasi dan riwayat penyakit.
\end{abstract}

Kata kunci : kualitas hidup, mahasiswa profesi apoteker, SF-36, SF-6D 


\section{ABSTRACT}

Individual quality of life is affected by health status. The quality of life can be measured whether a person is in health or sick condition. The measurement used the Short Form 36 (SF-36) questionnaires. This research aimed to know the score of quality of life and factors that affect student's quality of life. This study used a cross sectional design. Sampelts are Pharmacy XXXI students at Faculty of Pharmacy, Ahmad Dahlan University were given a SF-36 questionnaire and form the characteristics of sampelts. Analysis for the SF-36 is mapped to the SF-6D and characteristic data is expressed in percentage. Analysis of the relationship between characteristics sampelts and quality of life conducted by Mann-Whitney and Kruskal-Wallis test. Subject in the study are 126 student. The results of the quality of life of pharmacist student in SF $6 D$ were showed 0.739 scores. The test results between quality of life and characteristics showed that there is a correlation of quality of life in transportation types $(p=0.039)$ and history of disease $(p=0.01)$. The results show that the score of student's quality of life in SF-6D of SF Indeks is 0.739. In conclussion, the factors that affect quality of life in the pharmacist student are transportation types and history of disease.

Keywords: quality of life, pharmacist student, SF-36, SF-6D

\section{PENDAHULUAN}

Kualitas hidup bagi beberapa negara merupakan suatu isu prioritas. Sejak jaman dahulu manusia telah berupaya untuk melakukan peningkatan kualitas hidup (Molnar, 2009). Gambaran dari kualitas hidup seseorang akan menjadi acuan untuk mengetahui tingkat kesejahteraan individu dalam suatu masyarakat. Beberapa orang memandang suatu kualitas hidup berhubungan dengan kebutuhan dasar seperti kebutuhan sandang, pangan, papan, dan pendidikan (Muhaimin, 2010).

Blum menyatakan seperti yang disitasi oleh Notoadmodjo (2003), bahwa kesehatan seseorang dipengaruhi oleh empat faktor yaitu kesehatan fisik, kesehatan lingkungan, kesehatan mental atau psikis, serta fasilitas pelayanan kesehatan. Pengukuran kesehatan mengenai kualitas hidup tidak hanya dilakukan pada individu sakit, karena individu sakit memiliki kecenderungan kualitas hidup yang buruk. Individu yang normal dapat memiliki kualitas hidup yang buruk ditinjau dari faktor fisik dan mental individu. Beberapa individu yang secara fisik sehat dapat memiliki kualitas hidup lebih rendah daripada individu yang sakit. 
Pengukuran kualitas hidup pada mahasiswa dilakukan untuk mengetahui sejauh mana kualitas hidup individu sehat. Sistem kurikulum di perguruan tinggi mengharuskan mahasiswa dapat mengikuti sistem tersebut dengan proporsi yang banyak dan terkadang waktu yang tidak memadai. Selain itu, sistem pembelajaran yang selalu dilihat dari hasil yang di capai menuntut mahasiswa untuk dapat maksimal yang terkadang tanpa memperhatikan elemen lainnya. Hal-hal yang menjadi pemicu mempengaruhi pada kesehatan fisik dan mental mahasiswa. Mahasiswa yang kuliah di bidang kesehatan mengalami sistem pembelajaran yang berbeda dengan mahasiswa kuliah di bidang lain. Pembelajaran itu seperti kegiatan praktek di lapangan, eksperimen, dan beban kuliah (Zhang, 2012).

Berdasarkan alasan tersebut di atas menarik perhatian penulis untuk mempelajari kualitas hidup mahasiswa yang mengikuti Program Studi Profesi Apoteker. Penelitian ini bertujuan untuk mengetahui skor kualitas hidup dan faktor-faktor yang mempengaruhi kualitas hidup pada mahasiswa program studi Profesi Apoteker.

\section{METODE PENELITIAN}

Rancangan penelitian ini adalah cross sectional design. Populasi dalam penelitian ini adalah mahasiswa program Studi Profesi Apoteker di Fakultas Farmasi Universitas Ahmad Dahlan (UAD). Sampel dalam penelitian ini adalah mahasiswa Program Studi Profesi Apoteker angkatan XXXI tahun 2016. Pengambilan sampel penelitian dilakukan sesuai dengan kriteria inklusi dan ekslusi. Kriteria inklusi penelitian ini adalah : mahasiswa aktif pada Program Studi Profesi Apoteker XXXI tahun 2016 di Fakultas Farmasi Universitas Ahmad Dahlan, mahasiswa bersedia terlibat dalam penelitian ini dengan mengisi kuisioner secara lengkap. Kriteria eksklusi penelitian ini adalah mahasiswa yang mengisi kuisioner secara tidak lengkap dan mahasiswa yang mengundurkan diri.

Alat yang digunakan dalam penelitian ini berupa kuisioner Short Form (SF-36) yang sudah diterjemahkan ke dalam versi Indonesia. Kuisioner ini sebelum digunakan telah divalidasi dan memenuhi persyaratan untuk digunakan. Skor SF Indeks $\mathrm{p}=0,07$ dimana $\mathrm{p}$ lebih besar dari 0,05 sehingga sebaran data SF 
Indeks terdistribusi normal. Sebaran data diperoleh nilai rata rata SF Indeks sebesar 0,739 dengan simpang baku sebesar 0,076. Sebanyak 126 responden tetap mendapatkan nilai SF Indeks minimum sebesar 0,569 dan maksimum nilai SF Indeks sebesar 0,904 .

Analisis Data

1. Skoring Kuisioner SF-36

Dalam penelitian ini skoring data berasal dari kuisioner SF-36 yang ditransformasikan ke SF- 6D. Berdasarkan tabel pemetaan maka hasil kuisioner SF-36 yang telah diisi sampel ditransformasikan ke SF-6D. Jika telah dilakukan pemetaan maka dapat dilakukan perhitungan SF Indeks, yaitu dengan rumus sebagai berikut :

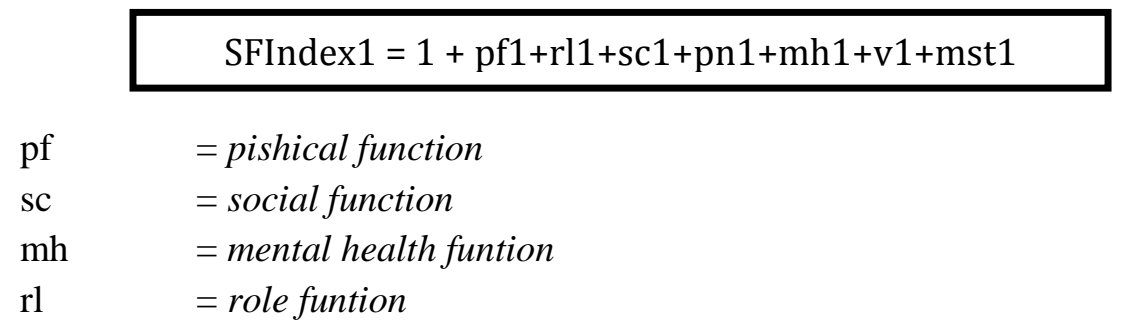

Dimana nilai mst1 diperoleh dari, yaitu :

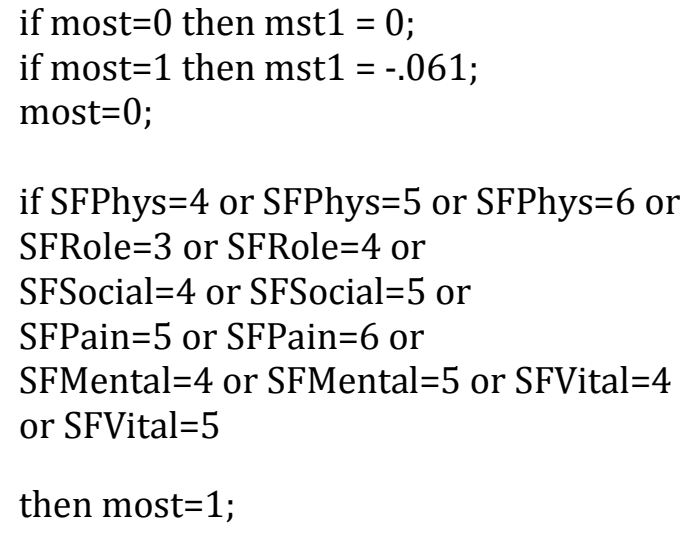

SF indeks dihitung dari transformasi SF-36 ke SF-6D dilihat dari masingmasing item tiap domain pertanyaan. SF Indeks akan memberikan gambaran dari hasil pengukuran kualitas hidup. Hasil SF-6D indeks mempunyai skor 1 dan 0 , 
dimana 0 adalah kesehatan buruk dan 1 adalah kesehatan yang terbaik (NHMS, 2008).

\section{Analisis Statistik}

Analisis statistik dilakukan dengan menentukan skor kualitas hidup melalui transformasi SF-6D dari SF-36 yang hasilnya menunjukkan skor SF-Indeks. Skor kualitas hidup selanjutnya digunakan untuk penyajian data demografi mahasiswa berupa usia, jenis kelamin, transportasi, uang saku, riwayat penyakit dan pilihan minat dinyatakan dalam persentase dengan menggunakan frekuensi. Pengaruh faktor demografi pada kualitas hidup mahasiswa dianalisis dengan uji Mann-Whitney untuk data dua kelompok dan uji Kruskall-Wallis untuk data lebih dari dua kelompok.

\section{HASIL DAN PEMBAHASAN}

Karakteristik demografi responden tersaji pada tabel I.

Tabel I. Data demografi Mahasiswa Program Studi Profesi Apoteker angkatan XXXI tahun 2016 Fakultas Farmasi Universitas Ahmad Dahlan Yogyakarta

\begin{tabular}{llcc}
\hline & \multicolumn{1}{c}{ Variabel } & $\mathbf{N}$ & $\mathbf{( \% )}$ \\
\hline Usia (tahun) & $20-23$ & 77 & 61,1 \\
& $24-26$ & 49 & 38,9 \\
\hline Jenis Kelamin & Laki-Laki & 20 & 15,9 \\
& Perempuan & 106 & 84,1 \\
\hline \multirow{2}{*}{ Transportasi } & Jalan Kaki & 32 & 25,4 \\
& Sepeda & 2 & 1,6 \\
& Sepeda Motor & 90 & 71,4 \\
& Mobil & 2 & 1,6 \\
\hline Uang Saku (Rp) & $<1.000 .000$ & 27 & 21,4 \\
& $1.000 .000-2.000 .000$ & 90 & 71,4 \\
& $>2.000 .000$ & 9 & 7,1 \\
\hline Riwayat Penyakit & Ya & 26 & 20,6 \\
& Tidak & 100 & 79,4 \\
\hline Minat & Farmasi Klinis/ Rumah Sakit & 111 & 88,1 \\
& Farmasi Industri/ Bahan Alam & 15 & 11,9 \\
\hline
\end{tabular}

Hubungan nilai Kualitas Hidup dengan Karakteristik Sampel

Hubungan kualitas hidup mahasiswa Program Profesi Apoteker UAD dengan faktor demografi yang mempengaruhi kualitas hidup, tersaji pada tabel II dan III. 
Tabel II. Hasil Analisis Uji Mann-Whitney antara Karakteristik dengan Kualitas Hidup

\begin{tabular}{|c|c|c|c|}
\hline & & $\begin{array}{l}\text { Mean (Minimum - } \\
\text { Maksimum) }\end{array}$ & $\mathbf{P}$ \\
\hline \multirow{2}{*}{ Usia } & $20-22$ tahun & $0,741(0,582-0,897)$ & \multirow{2}{*}{0,908} \\
\hline & 23-26 tahun & $0,736(0,569-0,904)$ & \\
\hline \multirow{2}{*}{ Jenis Kelamin } & Laki-Laki & $0,739(0,614-0,826)$ & \multirow{2}{*}{0,612} \\
\hline & Perempuan & $0,739(0,569-0,904)$ & \\
\hline \multirow{2}{*}{$\begin{array}{l}\text { Riwayat } \\
\text { Penyakit }\end{array}$} & $\mathrm{Ya}$ & $0,700(0,569-0,866)$ & \multirow{2}{*}{$0,01^{*}$} \\
\hline & Tidak & $0,749(0,582-0,904)$ & \\
\hline \multirow{2}{*}{ Minat } & $\begin{array}{l}\text { Farmasi Klinis/ } \\
\text { Rumah Sakit }\end{array}$ & $0,739(0,569-0,904)$ & \multirow{2}{*}{0,851} \\
\hline & $\begin{array}{l}\text { Farmasi Industri/ } \\
\text { Bahan Alam }\end{array}$ & $0,738(0,614-0,843)$ & \\
\hline
\end{tabular}

*: terdapat perbedaan signifikan $(\mathrm{p}<0,05)$

Usia seseorang tidak berpengaruh secara signifikan pada kualitas hidup seseorang. Penelitian yang dilakukan pada sebuah populasi di Jerman menyatakan bahwa tidak ada perbedaan yang bermakna pada perbedaan usia terhadap kualitas hidup dan kesehatan seseorang, perbedaan gaya hidup dan kesadaran terhadap hidup sehat merupakan salah satu faktor yang menentukan baik dan tidaknya suatu kualitas hidup (Luy dan Paola, 2006). Jenis kelamin juga mempunyai pengaruh terhadap kualitas hidup seseorang. Penilaian kualitas hidup mahasiswa yang telah dilakukan tidak menunjukkan perbedaan bermakna pada perbedaan jenis kelamin. Perbedaan jenis kelamin ternyata mempunyai pengaruh terhadap gaya berpikir dan kondisi emosional seseorang, seperti yang dinyatakan dalam sebuah penelitian di Texas Amerika, ternyata perempuan mempunyai gaya berpikir dan tingkat emosional yang lebih baik dari pada laki laki, sehingga kualitas hidup mereka jauh lebih baik (Wendy et al, 1989).

Sehat merupakan kondisi sebaik baiknya pada jiwa dan raga, sehingga adanya sebuah penyakit tentu berpengaruh terhadap kualitas hidup seseorang , termasuk dalam hal ini adalah mahasiswa. Kualitas hidup merupakan sebuah konsep yang menunjukkan kondisi kesehatan fisik secara umum pada seseorang agar dapat berkarya dan produktif termasuk didalamnya sehat secara ekonomi, sosial, lingkungan, mental dan psikis (Messinal et al, 2016). 
Tabel III. Hasil Analisis Uji Kruskal-Wallis antara Karakteristik dengan Kualitas Hidup

\begin{tabular}{llccc}
\hline & Variabel & n & SF Indeks & P \\
\hline \multirow{5}{*}{ Transportasi } & Jalan Kaki & 32 & $0,719(0,616-0,897)$ & \\
& Sepeda & 2 & $0,665(0,638-0,692)$ & \multirow{2}{*}{$0,026^{*}$} \\
& Sepeda Motor & 89 & $0,745(0,569-0,904)$ & \\
& Mobil & 3 & $0,823(0,769-0,897)$ & \\
\hline \multirow{5}{*}{ Uang Saku } & $<$ Rp 1.000.00,00 & 27 & $0,716(0,614-0,904)$ & \\
& Rp 1.000.000,00- & & & \\
& Rp 2.000.000,00 & 90 & $0,730(0,569-0,897)$ & 0,470 \\
*: terdapat perbedaan signifikan $(p<0,05)$ & & & \\
& $>$ Rp 2.000.000,00 & 9 & $0,714(0,654-0,804)$ & \\
\hline
\end{tabular}

*: terdapat perbedaan signifikan $(\mathrm{p}<0,05)$

Berdasarkan hasil penelitian telah didapatkan skor nilai dari SF-36 yang menyatakan nilai kualitas mahasiswa. Skor nilai kualitas hidup mahasiswa dinyatakan dalam angka yaitu 0,736. Penelitian ini membuktikan karakteristik sampel berpengaruh pada kualitas hidup. Karakteristik yang berpengaruh dalam penelitian ini adalah jenis transportasi dengan nilai $\mathrm{p}$ sebesar 0,039 dimana jenis mobil memiliki nilai kualitas hidup paling tinggi. Karakteristik riwayat penyakit dengan nilai $\mathrm{p}$ sebesar 0,01 berpengaruh pada kualitas hidup yaitu pada mahasiswa yang tidak memiliki riwayat penyakit lebih tinggi nilai kualitas hidupnya. Penelitian ini menyimpulkan bahwa nilai kualitas hidup sampel sebesar 0,736 dan salah satu faktor yang dapat mempengaruhi kualitas hidup mahasiswa Profesi Apoteker UAD adalah penggunaan alat transportasi.

Laporan kasus dari Groningen Belanda menyatakan bahwa semakin banyak orang menggunakan alat transportasi sebagai pendukung kegiatan dan perjalanan dibanding dengan orang yang tidak menggunakan alat transportasi, sehingga ketersediaan alat trasnportasi erat kaitannya dengan kualitas hidup seseorang meskipun penggunaan alat transportasi seperti mobil akan berdampak pada aktivitas lain seperti biaya dan peraturan yang harus dipenuhi (Linda et al, 2005). Penelitian yang dilakukan pada pelajar atau mahasiswa di salah satu universitas Amerika Serikat, diketahui bahwa aktivitas fisik dan perilaku positif di sebuah lingkungan dapat meningkatkan rasa percaya diri, dimana percaya diri yang baik ada kaitannya dengan kualitas hidup mahasiswa (Joseph et al., 2014 ). Berbeda 
dengan pengukuran kualitas hidup yang dilakukan di salah satu universitas di Italia, bahwa kualitas hidup diukur berdasar pada kondisi yang menunjang keberhasilan belajar mahasiswa serta kondisi lingkungan yang biasa dilakukan oleh mahasiswa. Beberapa kondisi yang yang terukur dalam penelitian tersebut adalah penunjang belajar seperti perpustakaan, kualitas dosen, kantin dan staf pelayanan. Kondisi lain yang memperngaruhi kualitas hidup mahasiswa yang lain adalah hiburan malam, olahraga, belanja dan menyaksikan film di bioskop (Isabela dan Tedesco, 2009). Mahasiswa bidang kesehatan diketahui memiliki kualitas hidup yang lebih buruk dari pada masyarakat pada umumnya karena beban belajar mereka lebih tinggi termasuk aktivitas pembuatan laporan kasus (Jamali et al., 2013). Berdasarkan beberapa ulasan tersebut dapat diketahui bahwa secara empiris kualitas hidup mahasiswa ditentukan berbagai faktor dan kondisi yang berbeda pada subyek dan lokasi.

\section{KESIMPULAN}

Kualitas hidup mahasiswa Program Studi Profesi Apoteker Fakultas Farmasi UAD Yogyakarta yang diukur dengan SF-6D menunjukkan nilai SF Indeks sebesar 0,739. Karakteristik reponden yang mempengaruhi nilai kualitas hidup mahasiswa Program Studi Profesi Apoteker adalah transportasi $(\mathrm{p}=0,039)$ dengan nilai tertinggi pada kelompok mobil dengan rata-rata 0,823 dan riwayat penyakit $(\mathrm{p}=0,01)$ dengan nilai tertinggi pada kelompok tidak memiliki riwayat penyakit dengan rata-rata 0,749 .

\section{DAFTAR PUSTAKA}

Joseph.R, Kathryn E. Royse, Tanya J.Benitez,Dorothy W Pekmezi.,2014, Physical Activity and Quality of Life Among University Students: exploring self efficay,self esteem, and affect as potential mediators. National Intitutes Of health Public Access, Qual Life Res.March, 23 (2) : 659-667.

Jamali A, Tofangchiha S, Nedjat S,Narimani A, Jan D, Montazeri A.,2013, Medical Students health related quality of life : Roles of social and behavioral Factors. Tehran University Of Medical Sciences.

Linda Steg, Robert Gifford., 2005, Sustainable transportasion and quality of life, Journal of Trasnport Geography, 13, 59-69. 
Luy, M., Paola Di Giulio., 2006, Impact of health behaviors and life quality on gender differences in mortality. Max Planck Institute for Demographic Research.

Messinal G, Querciolli C, Barbini E, Troiano C, Nante N., 2016, Italian Medical Students quality of Life : years 2005-2015. Ann Ig 28:245-251.

Muhaimin, T., 2010, Mengukur Kualitas Hidup Anak. Jurnal Kesehatan Masyarakat Nasional, Vol.5 No.2: 51-55.

Molnar, P., 2009, Some Aspects of The Measurement and Improvement of Quality of Life, diakses pada 2 Februari 2016, http ://scribd.com/doc/10203667.

Notoadmodjo, S., 2003, Ilmu Kesehatan Masyarakat Prinsip-Prinsip Dasar. Jakarta : Rineka Cipta.

Notoatmodjo, S. 2012, Metode Penelitian Kesehatan. Edisi Revisi. Cetakan kedua 164-170. Rineka Cipta. Jakarta.

Isabela S., Nicola Tedesco., 2009, Measures of Quality of life Among University Students, Italian Journal of Applied Statistic,s, 21 (3) : 3-4.

The National Measurement Study (NHMS), 2008, Explanation of Computed Variables, University of Wisconsin-Madison Department of Population Health Sciences.

Wendy Wood, Nancy Rhodes, Melanie Whelan, 1989, Sex differences in positive well being : A consideration of emotionl style and marital Status. Psycological Bulletin The American Phychological Association , 106 (2), 249-264.

Zhang, Y., Qu, B., Lun, Shi-si., Guo, Yi., and Liu, J., 2012, The 36-Item Short Form Health Survey : Reliability and Validity in Chinese Medical Student, International Journal of Medical Sciences, 9 (7):521-526. 